Artigos

Alcinéa Meigikos dos Anjos Santos

Raul Zanoni Lopes Cançado ${ }^{2}$

Roberto Meigikos dos Anjos ${ }^{3}$

Norma Conceição do Amaral ${ }^{1}$

Leila Cristina Alves Lima'

\section{Características da exposição ocupacional a poeiras em marmorarias da cidade de São Paulo*}

\author{
Characteristics of occupational exposure to dust in the work \\ environment of marble shops in the city of São Paulo
}

${ }^{1}$ Fundacentro. Divisão de Agentes Químicos. Coordenação de Higiene do Trabalho. São Paulo, Brasil.

${ }^{2}$ Departamento de Engenharia de Minas. Universidade Federal de Minas Gerais. Minas Gerais, Brasil.

${ }^{3}$ Instituto de Física. Universidade Federal Fluminense. Rio de Janeiro, Brasil.

*Artigo baseado na tese de doutorado de Alcinéa Meigikos dos Anjos Santos intitulada Exposição ocupacional a poeiras em marmorarias: tamanhos de partículas característicos, apresentada em 2005 ao Departamento de Engenharia de Minas, Escola de Engenharia da Universidade Federal de Minas Gerais.

Contato:

Alcinéa Meigikos dos Anjos Santos Fundacentro - Rua Capote Valente, 710 - Pinheiros

Fone: (11) 3066-6227 / 6392 / 6033

E-mail:

alcinea@fundacentro.gov.br

\section{Resumo}

O estudo das características da exposição ocupacional a poeiras no beneficiamento de rochas ornamentais em marmorarias teve como base a aplicação das convenções adotadas pela American Conference of Governmental Industrial Hygienists (ACGIH), pela International Organization for Standardization (ISO) e pelo Comité Europeén de Normalisation (CEN) para a classificação de poeiras por faixa de tamanhos de partícula. Foram consideradas as relações entre as concentrações de poeira nos ambientes de trabalho, os tipos de rochas trabalhadas, as operações a úmido e a seco, as máquinas e as ferramentas utilizadas e os tamanhos das partículas suspensas no ar. Os ambientes de trabalho das marmorarias mostraram altas concentrações de poeira nas frações inalável, torácica e respirável, originadas pelas ferramentas utilizadas no setor de acabamento a seco. As concentrações de sílica chegaram a ser 16 vezes superiores ao valor do limite de exposição ocupacional de $0,05 \mathrm{mg} / \mathrm{m}^{3}$. A avaliação de uma marmoraria que adotou acabamento a úmido mostrou que a probabilidade das concentrações ambientais ultrapassarem os valores de referência ocupacionais pôde ser reduzida em até 99\%.

Palavras-chaves: marmoraria, poeira, sílica, silicose, higiene ocupacional.

\section{Abstract}

This paper reports a study based on the application of conventions adopted by the American Conference of Governmental Industrial Hygienists (ACGIH), International Organization for Standardization (ISO) and Comité Europeén de Normalisation (CEN) for the classification of types of dust by particle size range. The occupational exposure characterization took into account the relations among dust concentrations at workplace, types of rocks worked on, wet and dry operations, machinery and tools used, and the size distribution of particles suspended in the air. The workplaces at the marble shops were characterized by high concentrations of dust in inhalable, thoracic and respirable fractions, produced by the tools used in the dry abrasive polishing sector. The silica concentrations were up to 16 times higher than the $0.05 \mathrm{mg} / \mathrm{m}^{3}$ occupational exposure limit recommended. The evaluation of a marble shop that made use of the wet abrasive polishing process showed that the probability of environmental concentrations exceeding the occupational reference values could be reduced by up to $99 \%$.

Keywords: marble shop, dust, silica, silicosis, occupational hygiene. 


\section{Introdução}

O Estado de São Paulo destaca-se como o maior centro consumidor de rochas ornamentais do país e responde por cerca de $70 \%$ do consumo nacional de mármores e granitos beneficiados. Estima-se que existam quase 3.000 marmorarias distribuídas por 157 municípios, sendo mais de 1.000 delas localizadas na cidade de São Paulo (MELLO, 2000). Devido à relativa simplicidade do processo produtivo, é comum encontrar empresas instaladas com investimento reduzido e pequeno número de funcionários, geralmente com pouca qualificação. Esse conjunto de características vem acompanhado da falta de informação por parte de trabalhadores e empregadores com relação aos riscos ocupacionais típicos deste ramo de atividade.

Dentre os principais riscos encontrados nas marmorarias está a exposição a poeiras, favorecendo o aumento de doenças do sistema respiratório, principalmente a silicose. Devido à importância e à gravidade dessa doença e ao número elevado de trabalhadores expostos a poeiras nas marmorarias, esse é um dos ramos de atividade considerados prioritários pelo Programa Nacional de Eliminação da Silicose, instituído e coordenado pela Fundacentro desde 2001.

A poeira suspensa no ar das marmorarias é constituída da mistura do particulado gerado pelas diversas rochas trabalhadas: mármores, granitos e ardósias, além de outras em menor proporção. Entre as principais rochas utilizadas em marmorarias, o granito é a que contém os maiores teores de sílica. Esses teores são variáveis na rocha bruta, dependendo de seu tipo, sendo que nos granitos são superiores a $65 \%$ e nas ardósias podem chegar a 30\%. Os mármores geralmente não contêm sílica, com exceção do mármore travertino, que possui incrustações de areia com teores de até 15\% (ABIROCHAS, 2003). Na poeira suspensa no ar, os teores de sílica são diferentes desses, pois dependem da densidade de cada partícula componente da poeira e de outros fatores que afetam a dispersão dessas partículas no ar.

O processo produtivo das marmorarias consiste em recebimento das chapas pré-polidas, corte das peças nas medidas solicitadas pelos clientes, desbaste e polimento de bordas e superfícies, montagem e acabamento final da peça. As ferramentas manuais mais utilizadas no setor de acabamento são a lixadeira manual elétrica, a serra manual elétrica (serra-mármore) e o esmeril reto (chicote).

Após o corte, as peças são levadas para as bancadas de acabamento, onde se executam as operações de desbaste e lixamento para dar forma a bordas e cantos. Geralmente, essa etapa é realizada a seco por meio da utilização de lixadeiras, às quais são acoplados rebolos, discos de desbaste ou lixas abrasivas de diversas granulometrias, de acordo com o tipo de acabamento desejado. O movimento de vai-e-vem lateral e vertical, característico do acabamento das bordas e superfícies das rochas, propicia o espalhamento da poeira em direção às vias respiratórias dos trabalhadores que manuseiam a ferramenta e em direção aos colegas de trabalho que executam suas atividades nas proximidades.

As atividades de furação e corte são tipicamente executadas a úmido, com alimentação de água especialmente destinada para essa finalidade. Porém, na grande maioria dos casos, não há segregação entre os setores de corte e acabamento, favorecendo a socialização da exposição dos trabalhadores aos vários agentes agressores presentes no ambiente, tais como o ruído e os componentes das colas utilizadas para montagem de peças, além, é claro, da própria poeira.

O critério para a seleção das marmorarias avaliadas neste estudo levou em consideração a execução de atividades consideradas como representativas das situações de trabalho mais comuns na maioria das marmorarias da cidade de São Paulo e a existência de algum tipo de iniciativa de implantação de medida de controle de caráter coletivo para a redução da exposição à poeira. Por meio desse critério, pretendia-se observar as soluções de controle já adotadas para a mitigação do problema e verificar seu desempenho em situações reais de trabalho. A comparação das soluções adotadas possibilitaria a troca de experiências entre marmorarias e a recomendação das soluções mais eficazes.

A exposição ocupacional a poeiras nas marmorarias foi avaliada utilizando a convenção de amostragem adotada internacionalmente pela American Conference of Governmental Industrial Hygienists (ACGIH,1993), pela International Organization for Standardization (ISO, 1992) e pelo Comité Europeén de Normalisation (CEN, 1992) para a classificação de poeiras por faixa de tamanhos de partícula. A convenção ACGIH/ISO/CEN relaciona os tamanhos das partículas coletadas com o tipo de efeito à saúde com o qual elas podem estar associadas. Para tanto, são levados em conta fatores físicos e biológicos relevantes para a determinação da exposição, fundamentados, por sua vez, na dose e no efeito do agente de risco e refletindo o processo aerodinâmico que faz com que as partículas entrem no corpo humano durante a respiração e se depositem em partes específicas do trato respiratório (VINCENT, 1986). Dependendo dos efeitos à saúde, uma ou mais regiões serão de maior interesse, conforme as definições a seguir:

- Fração de particulado inalável é aquela fração de uma nuvem de poeira suspensa no ar que pode entrar pelo nariz ou pela boca. É composta por partículas menores que 100 micrometros, sendo capaz de penetrar em várias regiões do trato respiratório, à medida que seu tamanho diminui, até chegar aos alvéolos. Essa fração da poeira pode ser absorvida pelo corpo e causar efeitos sistêmicos, dependendo de sua toxicidade, quando a partícula é solúvel nos fluídos 
do corpo, ou pode causar um efeito direto no local da deposição (ACGIH, 2005).

- Fração de particulado torácico é uma subfração da fração inalável composta por partículas menores que 25 micrometros, podendo penetrar nas vias aéreas superiores e entrar nas vias aéreas dos pulmões. Essa fração da poeira é responsável por efeitos locais, como broncoconstrição, asma, agravamento de bronquite crônica ou indução de tumores broncogênicos (ACGIH, 2005).

- Fração de particulado respirável é uma subfração da fração torácica do ar inalado composta pelas partículas menores que 10 micrometros, sendo capaz de penetrar além dos bronquíolos terminais, entrando na região alveolar. A amostragem da fração respirável é sugerida quando a poeira é insolúvel e a doença está associada com a região de troca de gases do pulmão, como as doenças fibrogênicas (silicose, por exemplo) ou enfisema pulmonar (ACGIH, 2005).

Assim, com o objetivo de estudar as características da exposição ocupacional a poeiras no beneficiamento de rochas ornamentais em marmorarias e obter informações sobre a poeira presente nesses ambientes de trabalho, foram coletadas amostras nas frações inalável, torácica e respirável simultaneamente. Para tanto, foram selecionadas 10 marmorarias, localizadas em diversas regiões da cidade de São Paulo, para a execução dos trabalhos experimentais de campo. A seleção foi baseada no levantamento realizado pelos Centros de Referência em Saúde do Trabalhador em conjunto com o Ministério Público do Estado de São Paulo como parte do Projeto Marmoristas (MPESP, 2001). As marmorarias foram visitadas antes do início dos trabalhos de coleta para verificação de seu enquadramento nos critérios estabelecidos com relação aos tipos de medidas de controle de caráter coletivo adotadas para a redução da concentração de poeira nos ambientes de trabalho. Foram coletadas cerca de 200 amostras nos dois principais setores produtivos das marmorarias (acabamento e corte) de maneira a permitir a observação das variações típicas decorrentes dos procedimentos geradores da poeira. A partir dessas informações, foi possível avaliar o nível de exposição dos trabalhadores durante a jornada de trabalho, as características dessa exposição nas marmorarias selecionadas e a eficiência das medidas de controle, sendo que os principais resultados são mostrados neste artigo.

\section{Materiais e métodos}

Cada uma das marmorarias foi avaliada durante 5 a 6 horas/dia por 3 dias da mesma semana de trabalho, correspondendo à observação de cerca de 70\% da jornada de trabalho diária e semanal (Santos, 2005).

Foram coletadas 108 amostras individuais, com o amostrador colocado na zona respiratória dos trabalhadores que desenvolviam atividades utilizando lixadeiras e serras elétricas manuais, para avaliar a exposição direta do trabalhador durante a execução de atividades de acabamento. Também foram coletadas 41 amostras de área, com o amostrador colocado em ponto fixo no setor de acabamento, em local de circulação comum aos trabalhadores, próximo às principais fontes geradoras de poeira, para avaliar a concentração ambiental como indicativo da exposição indireta dos trabalhadores e a eficiência das medidas de controle existentes. No setor de corte, foram coletadas 38 amostras individuais para avaliação da influência da poeira gerada no setor de acabamento sobre os trabalhadores que executavam atividades a úmido. Além disso, 12 amostras foram coletadas em uma marmoraria que trabalhava com processo a úmido no setor de acabamento.

Para a coleta das amostras de poeira, foi utilizado um tipo especial de impactador virtual, conhecido comercialmente como amostrador Respicon (TSI, 1997), capaz de separar as partículas de poeira nas frações inalável, torácica e respirável, de acordo com as convenções da ACGIH/ISO/CEN. Nesse amostrador, três filtros de coleta e dois impactadores virtuais são montados em uma unidade compacta concêntrica com simetria cilíndrica. O fluxo total é controlado com uma bomba de amostragem individual convencional, calibrada na vazão total de $3,11 \mathrm{~L} / \mathrm{min}$. A separação em cada estágio é controlada por um orifício de fluxo que fraciona a vazão inicial. A poeira entra no amostrador passando através de um bocal central de aceleração que se dirige para o tubo coletor. Dentro do amostrador, as partículas da amostra de ar são separadas nas frações inalável, torácica e respirável. Partículas grossas passam direto pelo tubo coletor, enquanto as demais partículas são aerodinamicamente separadas nos filtros existentes em cada estágio do impactador. Os filtros dos estágios 1 e 2 possuem um orifício central que permite a passagem das partículas pelo tubo coletor até chegarem ao filtro final do estágio 3 , que não possui orifício. O material coletado no filtro do estágio 1 corresponde à fração respirável da poeira. A soma dos materiais coletados nos filtros dos estágios 1 e 2 corresponde à fração torácica e a soma dos materiais coletados nos filtros 1, 2 e 3 corresponde à fração inalável. A Figura 1 apresenta uma ilustração do esquema de funcionamento do impactador virtual.

As amostras foram coletadas sobre filtros de membrana de PVC de 5,0 $\mu \mathrm{m}$ de poro. Os filtros contendo o material particulado de cada uma das três frações foram analisados por gravimetria (SANTOS, 2001) para determinação das concentrações de poeira. A fração respirável de cada amostra também foi analisada por difração de raios-X (DRX) para verificação da presença de sílica livre cristalizada e quantificação de seu teor (SANTOS, 1989).

Os métodos estatísticos utilizados para o tratamento e a interpretação dos dados de avaliação da exposição ocupacional a poeiras basearam-se no fato de que as concentrações medidas a partir de amostras 


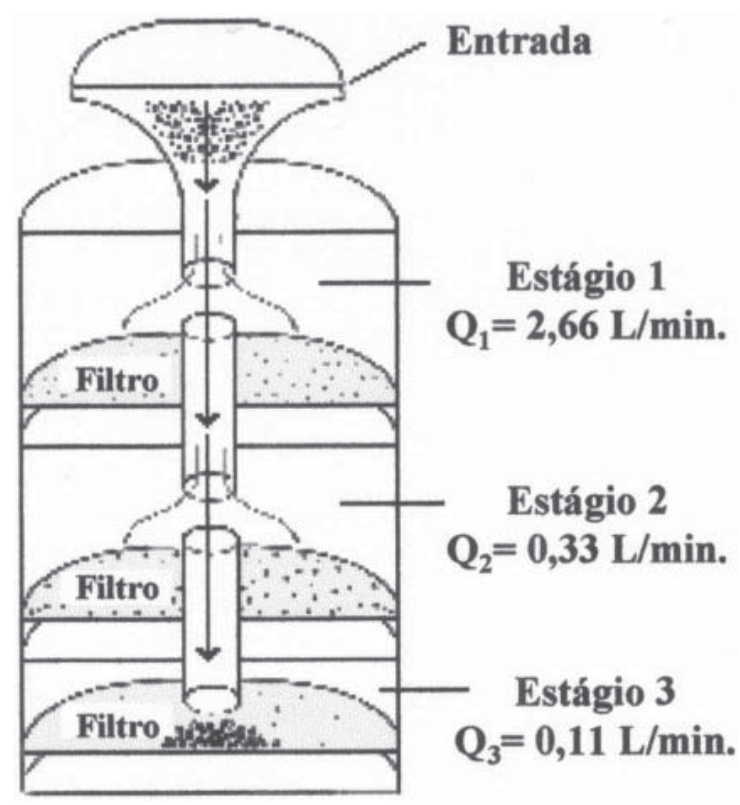

Figura 1 Ilustração do funcionamento de um impactador virtual

Fonte: TSI INCORPORETED, HEALTH AND SAFETY INSTRUMENTS DIVISION. How a virtual impactor works. TSI Application Note ITI-051. St. Paul, Minessota: TSI, 1997. Disponível em http://www.tsi.com. Acesso em: 20 abril 2002.

ambientais respondem a uma distribuição lognormal, levando-se em conta que as concentrações ambientais apresentam variações acentuadas (LEIDEL, BUSH \& LYNCH, 1977). Uma vez que a distribuição lognormal é uma distribuição normal dos logaritmos dos valores medidos, podem-se obter os valores de tendência central e de dispersão da mesma maneira que na distribuição normal. Assim, a tendência central é a média geométrica para a distribuição lognormal e a dispersão é o desvio padrão geométrico, mostrando a variabilidade ambiental.

O modelo utilizado por Leidel, Bush e Lynch (1977) para avaliação do nível de exposição ao longo do tempo, baseado no fato de que as distribuições das exposições médias são lognormais, estima a probabilidade da concentração de poeira em ultrapassar um valor recomendado (ou de referência) nas condições ambientais encontradas durante as medições. A representação gráfica, em escala log-probabilística, do conjunto de valores medidos é uma reta da qual se podem obter diretamente a média geométrica, o desvio padrão geométrico e a probabilidade de um valor de referência ser ultrapassado.

O procedimento prático simplificado para o tratamento dos dados experimentais consiste em ordenar os valores medidos de maneira crescente e calcular, para cada um deles, sua posição em um diagrama de probabilidades, conforme exemplificado na Tabela 1. Essa posição é uma função do número de valores obtidos e pode ser determinada a partir de planilhas de demarcação gráfica que representam uma distribuição normal ou por uma expressão simplificada, em que:

$$
P_{i}=\frac{100 i}{(N+1)} \quad \text { (equação 01) }
$$

sendo $P_{i}$ a posição do valor de ordem i, $\mathrm{N}$ o número de valores demarcados em gráfico e $i$ o número de ordem.

Os dados podem ser demarcados em papel logprobabilístico, no qual um dos eixos está em escala logarítmica e o outro em valores de probabilidade acumulada. Neste estudo, em particular, o eixo das probabilidades foi transformado em valores de probit. A transformação probit é um modelo de regressão que considera as funções acumuladas de probabilidade associadas à distribuição de probabilidade Gaussiana. Os probits indicam quantos desvios padrão da média o valor porcentual representa para uma distribuição normal (WILLEKE, 1993). Os valores porcentuais e seus valores correspondentes de probits são apresentados na Tabela 2.

A média está situada no probit $=0$, correspondente a $50 \%$ de probabilidade de freqüência acumulada abaixo de um determinado valor demarcado no diagrama (no presente estudo, a concentração). O desvio padrão é obtido dividindo-se o valor correspondente a $84,1 \%$ no eixo das concentrações (probit $=+1$ ) pelo valor correspondente a $50 \%($ probit $=0)$. Outros valores de probit podem ser obtidos por meio da Equação 02, sendo F o valor porcentual em centésimos de unidade:

$$
\text { probit } \left.=4,9\left(\mathrm{~F}^{0,14}-(1-\mathrm{F})^{0,14}\right) \quad \text { (equação } 02\right)
$$


Tabela 1 Exemplo de cálculo das posições dos dados de concentração medidos para posicionamento em um diagrama de probabilidades acumuladas, conforme Equação 01

\begin{tabular}{c|c|c|c}
\hline $\begin{array}{c}\text { Concentração } \\
\left(\mathrm{mg} / \mathrm{m}^{3}\right)\end{array}$ & \multicolumn{1}{c}{$N^{\circ}$ de ordem } & Pi $(\%)$ & Probit \\
\hline 1,0 & 1 & 7,7 & $-1,4$ \\
1,1 & 3 & 15,4 & $-1,0$ \\
1,4 & 23,1 & $-0,7$ \\
1,7 & 4 & 30,8 & $-0,5$ \\
1,8 & 5 & 38,5 & $-0,3$ \\
2,5 & 6 & 46,2 & $-0,1$ \\
2,6 & 7 & 53,8 & 0,1 \\
2,6 & 8 & 61,5 & 0,3 \\
3,2 & 9 & 69,2 & 0,5 \\
3,3 & 10 & 76,9 & 0,7 \\
3,7 & 11 & 84,6 & 1,0 \\
4,0 & 12 & 92,3 & 1,4 \\
\hline
\end{tabular}

O modelo de avaliação do nível de exposição ao longo do tempo leva em consideração a variabilidade das concentrações em ambientes de trabalho e recomenda a implantação de medidas de controle adequadas ao agente contaminante ou melhoria daquelas já instaladas, quando a probabilidade do valor de referência a ser ultrapassado for superior a $5 \%$.

Para interpretação dos resultados da avaliação ambiental apresentados neste estudo, foram adotados como valores de referência os Limites de Exposição Ocupacional (LEO) ${ }^{4}$ recomendados pela ACGIH (2005), observando-se os critérios descritos a seguir em ordem crescente de prioridade:

1. Uma vez que o maior valor estabelecido para o LEO para poeiras na fração inalável é de $10 \mathrm{mg} / \mathrm{m}^{3}$, considera-se que, independentemente da composição da poeira, a concentração não deve ultrapassar esse valor nessa fração em nenhum ambiente de trabalho.

2. Uma vez que o maior valor estabelecido para o LEO para poeiras na fração respirável é de $3 \mathrm{mg} / \mathrm{m}^{3}$, considera-se que, independentemente da composição da poeira, a concentração não deve ultrapassar esse valor nessa fração em nenhum ambiente de trabalho.
3. Considerando os agravos à saúde provocados pela presença da sílica livre cristalizada na poeira suspensa no ar na fração respirável e seu potencial carcinogênico reconhecido pela IARC (1997), aplicou-se o LEO de $0,05 \mathrm{mg} / \mathrm{m}^{3}$ por ser mais restritivo que aquele fixado pela legislação brasileira por meio da NR-15, anexo 12. Apesar de existir um LEO de 10 $\mathrm{mg} / \mathrm{m}^{3}$ para poeira de carbonato de cálcio (componente de diversos tipos de mármores), a exposição à sílica é, sem dúvida, mais nociva à saúde. Mesmo em marmorarias que declaravam executar trabalhos especializados em mármores, foi observado algum tipo de trabalho com granito.

As incertezas experimentais provenientes do processo de medição das concentrações foram estimadas levando-se em conta basicamente os erros de determinação da massa e do volume de ar amostrado, sendo de $5 \%$ o máximo valor de erro relativo aceito para as bombas de amostragem individual, de $4 \%$ a $6 \%$ para as massas obtidas por gravimetria e de $5 \%$ para a massas de sílica obtidas por DRX. Estima-se que as incertezas finais para os valores de concentração foram da ordem de $9 \%$ a $11 \%$ para as frações inalável, torácica e respirável e de 10\% para sílica na fração respirável.

${ }^{4}$ LEO (Limite de Exposição Ocupacional): valor de referência que se refere à concentração das substâncias dispersas no ar de ambientes de trabalho que representam as condições sob as quais se preconiza que a maioria dos trabalhadores possam estar expostos contínua e diariamente, sem apresentar efeitos adversos à saúde. (ACGIH. American Conference of Governmental Industrial Hygienists. 2006 Threshold Limit Values for Chemical Substances and Physical Agents and Biological Exposure Indices. Cincinnati, OH: ACGIH, 2006) 
Tabela 2 Valores porcentuais de referência em uma distribuição de probabilidade Gaussiana e seus valores correspondentes de probits

\begin{tabular}{cc}
\hline Valor porcentual & Probit \\
\hline 0,003 & $-4,0$ \\
0,023 & $-3,5$ \\
0,135 & $-3,0$ \\
0,621 & $-2,5$ \\
2,275 & $-2,0$ \\
6,681 & $-1,5$ \\
15,866 & $-1,0$ \\
30,854 & $-0,5$ \\
50,000 & 0,0 \\
69,146 & $+0,5$ \\
84,134 & $+1,0$ \\
93,319 & $+1,5$ \\
97,725 & $+2,0$ \\
99,379 & $+2,5$ \\
99,865 & $+3,0$ \\
99,977 & $+3,5$ \\
99,997 & $+4,0$ \\
\hline
\end{tabular}

\section{Resultados}

As coletas de amostras de poeira suspensa no ar nas marmorarias foram realizadas no período de abril de 2003 a junho de 2004. Nesse período, três das marmorarias selecionadas (2, 6 e 8 ) foram avaliadas sem que o sistema de controle, inicialmente observado nas visitas de seleção, estivesse em funcionamento. Essa foi considerada como uma situação real de trabalho das marmorarias e por isso elas não foram descartadas da seleção. A Tabela 3 apresenta a situação de controle coletivo encontrada durante o período de avaliação de campo.

Uma vez que o setor de acabamento a seco foi identificado como o principal responsável pela geração da poeira, as amostras coletadas nas marmorarias foram separadas em três grupos:

- amostras individuais coletadas no setor de acabamento a seco (operadores de lixadeiras, chicote e serra-mármore): avaliação da exposição direta dos trabalhadores;

- amostras de área coletadas em pontos de circulação do setor de acabamento (dispersão da poeira e eficiência de medidas de controle): avaliação da exposição indireta dos trabalhadores;

- amostras individuais coletadas nos setores onde eram executadas atividades a úmido (operadores de corte tradicional, serra-ponte, furadeira e boleadeira): avaliação da influência da poeira gerada no setor de acabamento a seco.

Com o objetivo de avaliar a situação de exposição dos trabalhadores, os valores das concentrações nas frações inalável, torácica e respirável e das concentrações de sílica de cada um dos três grupos foram ordenados para posterior cálculo de suas posições (Pi) em um diagrama de distribuição de probabilidades por meio da Equação 02, conforme apresentado no Gráfico 1. Os valores de média e desvio padrão geométricos para cada uma das concentrações de poeira nos três grupos citados anteriormente foram, então, obtidos a partir de seus respectivos gráficos de probabilidade de freqüência acumulada e encontram-se dispostos na Tabela 4. A concentração média geométrica corresponde ao valor de probit $=0$ e o desvio padrão geométrico foi obtido dividindo-se o valor correspondente ao probit $=1$ pelo valor correspondente ao probit $=0$. 
Tabela 3 Tipos de medidas coletivas de controle utilizadas para a redução da exposição ocupacional a poeiras no setor de acabamento das marmorarias avaliadas na cidade de São Paulo no período de abril/2003 a junho/2004

\begin{tabular}{|c|c|c|c|}
\hline $\begin{array}{l}\text { Código da } \\
\text { marmoraria }\end{array}$ & $\begin{array}{l}N^{\circ} \text { total de } \\
\text { trabalhadores } \\
\text { na produção }\end{array}$ & $\begin{array}{l}N^{\circ} \text { de trabalhadores } \\
\text { no acabamento }\end{array}$ & Tipos de medidas de controle encontradas durante o período de avaliação \\
\hline 1 & 08 & 06 & $\begin{array}{l}\text { Sistema de exaustão tipo tela, atendendo a } 2 \text { das } 10 \text { bancadas de } \\
\text { trabalho }\end{array}$ \\
\hline 2 & 10 & 06 & $\begin{array}{l}\text { Sistema de exaustão tipo coifa (desativado e desmontado durante o } \\
\text { período de avaliação) }\end{array}$ \\
\hline 3 & 10 & 07 & $\begin{array}{l}\text { Sistema de exaustão tipo coifa com } 3 \text { captores, localizados a } 1,5 \text { m acima } \\
\text { das bancadas, atendendo a } 5 \text { das } 8 \text { bancadas; } 1 \text { lixadeira para brilho } \\
\text { d'água }\end{array}$ \\
\hline 4 & 05 & 02 & $\begin{array}{l}\text { Processo produtivo totalmente a úmido (acabamento com lixadeiras } \\
\text { pneumáticas) }\end{array}$ \\
\hline 5 & 12 & 07 & $\begin{array}{l}\text { Sistema de exaustão tipo tela, localizado a } 1,0 \mathrm{~m} \text { das bancadas, atenden- } \\
\text { do a todo o setor de acabamento }\end{array}$ \\
\hline 6 & 12 & 08 & $\begin{array}{l}\text { Sistema de exaustão tipo tela em um único ponto do setor de acabamen- } \\
\text { to (desativado); boleadeiras automáticas a úmido }\end{array}$ \\
\hline 7 & 09 & 04 & $\begin{array}{l}\text { Exaustão de bancada com captura sob as bancadas e descarga em lâmina } \\
\text { d'água; uso de lixa espanhola }\end{array}$ \\
\hline 8 & 05 & 03 & $\begin{array}{l}\text { Declarou o uso de lixa espanhola (não usou lixadeiras durante o período } \\
\text { de avaliação); não havia exaustão }\end{array}$ \\
\hline 9 & 10 & 08 & $\begin{array}{l}\text { Sistema de exaustão em hélice com } 4 \text { captores, localizados a } 1,0 \text { m das } \\
\text { bancadas, com descarga em lâmina d'água que segue para tanque de } \\
\text { decantação; } 1 \text { lixadeira para brilho d'água }\end{array}$ \\
\hline 10 & 08 & 06 & $\begin{array}{l}\text { Sistema de exaustão em hélice com } 3 \text { captores, localizados a 1,0 } \\
\text { m das bancadas, com descarga a seco em segregado de alvenaria } \\
\text { dentro da área de produção }\end{array}$ \\
\hline
\end{tabular}

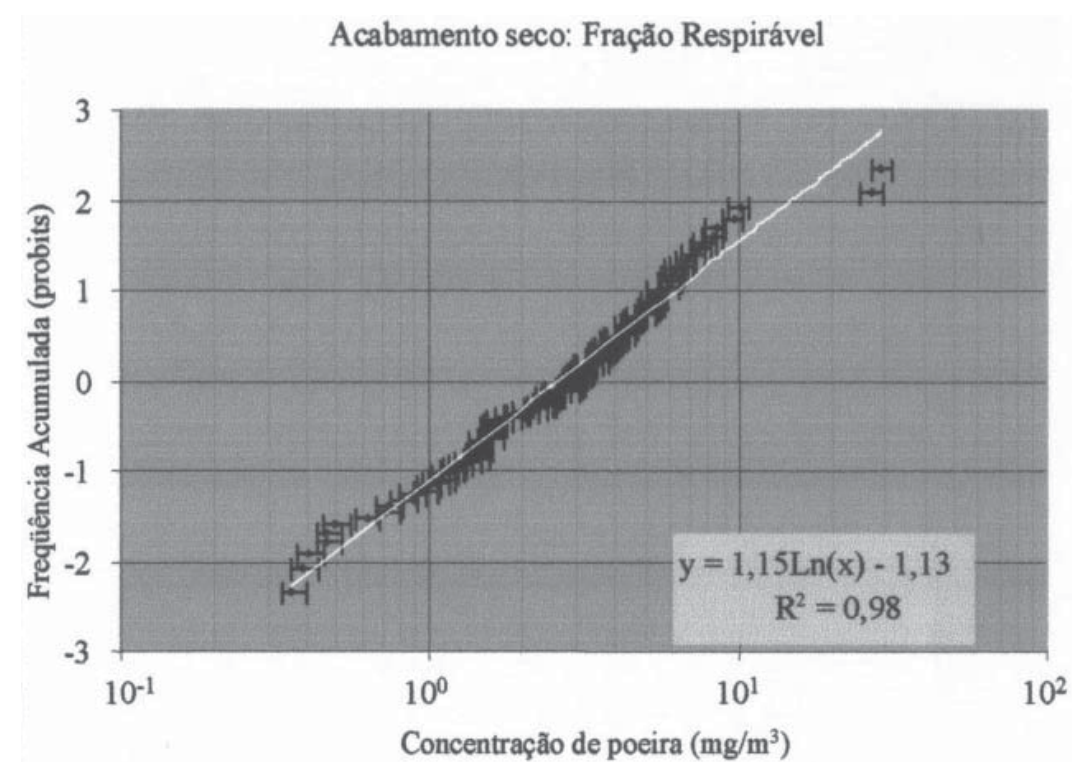

Gráfico 1 Probabilidade de freqüência acumulada (em unidades de probits) para as concentrações de poeira na fração respirável do setor de acabamento a seco das marmorarias avaliadas

Fonte: SANTOS, A. M. A. Exposição ocupacional a poeiras em marmorarias: tamanhos de partículas característicos. 2005. Tese (Doutorado em Engenharia Metalúrgica e de Minas), Escola de Engenharia, Departamento de Engenharia de Minas, Universidade Federal de Minas Gerais, 2005. 
Os valores apresentados na Tabela 4 mostram que as concentrações médias de poeira obtidas para todas as frações avaliadas são sempre mais elevadas no setor de acabamento a seco, diminuindo progressivamente nas amostragens de área e do setor de corte. As concentrações mínima e máxima mostram a grande variabilidade de valores obtidos.

\section{Marmoraria com processo de acabamento a úmido}

Diferentemente da situação apresentada anteriormente, a marmoraria 4 (Tabela 3) adotou a umidificação como medida de controle da exposição à poeira. A operação de acabamento era executada com lixadeiras pneumáticas movidas com água e ar comprimido. Além de não ter contato direto com o sistema elétrico da ferramenta, o trabalhador também foi aliviado do peso da lixadeira tradicional (cerca de $6 \mathrm{~kg}$ ) em comparação com a pneumática (cerca de 1,5 kg). Nas lixadeiras pneumáticas, a água é introduzida no ponto de geração da poeira, de maneira que as partículas se tornem úmidas antes de terem a chance de se dispersarem pelo ambiente, como já acontece para o corte de rochas nas marmorarias.

As 12 amostras provenientes da marmoraria 4 foram analisadas separadamente, como modelo de um processo produtivo totalmente a úmido, sem a interferência de poeira gerada em atividades executadas a seco. A separação de tais amostras foi mais conveniente, uma vez que nas demais marmorarias os setores que executavam atividades a úmido eram contaminados pelos setores de acabamento a seco (situação mais comum nas marmorarias de São Paulo).

Para efeito de comparação, os resultados das concentrações de poeiras nas frações inalável e respirável também foram tratados para o cálculo da probabilidade de sobreexposição, conforme já exemplificado no Gráfico 1. Os valores calculados para a determinação da probabilidade da concentração de exposição ultrapassar o valor de referência nessas frações são apresentados na Tabela 5.

Tabela 4 Exposição média dos trabalhadores às frações inalável, torácica, respirável e à sílica na fração respirável e probabilidades do valor de referência ser ultrapassado em cada fração de poeira avaliada em marmorarias da cidade de São Paulo no período de abril/2003 a junho/2004

\begin{tabular}{|c|c|c|c|c|c|c|}
\hline \multicolumn{2}{|c|}{ Exposição média } & $\begin{array}{c}\text { Concentrações mínima } \\
\text { e máxima medidas } \\
\left(\mathrm{mg} / \mathrm{m}^{3}\right)\end{array}$ & $\begin{array}{l}\text { Concentração } \\
\text { média } \\
\text { geométrica } \\
\left(\mathrm{mg} / \mathrm{m}^{3}\right)\end{array}$ & $\begin{array}{c}\text { Desvio } \\
\text { padrão } \\
\text { geométrico }\end{array}$ & $\begin{array}{c}\text { Intervalo de } \\
\text { confiança da } \\
\text { concentração média } \\
\left(\mathrm{mg} / \mathrm{m}^{3}\right)\end{array}$ & $\begin{array}{l}\text { Probabilidade do } \\
\text { valor de referência } \\
\text { ser ultrapassado }\end{array}$ \\
\hline \multirow{4}{*}{ 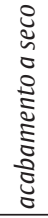 } & Fração Inalável & $2,0-245,0$ & 18,0 & 2,6 & $18,0-19,0$ & $70 \%$ \\
\hline & Fração Torácica & $1,0-76,0$ & 8,0 & 2,5 & $7,5-8,5$ & $*$ \\
\hline & Fração Respirável & $0,4-29,0$ & 2,7 & 2,3 & $2,3-3,1$ & $40 \%$ \\
\hline & Sílica & $N D-1,2$ & 0,2 & 2,6 & $0,0-0,8$ & $84 \%$ \\
\hline \multirow{4}{*}{ 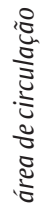 } & Fração Inalável & $0,8-47,0$ & 7,3 & 3,6 & $6,2-8,4$ & $38 \%$ \\
\hline & Fração Torácica & $0,4-21,0$ & 3,3 & 3,3 & $2,3-4,3$ & $*$ \\
\hline & Fração Respirável & $0,1-8,8$ & 1,3 & 2,8 & $1,9-3,7$ & $20 \%$ \\
\hline & Sílica & $N D-1,2$ & 0,1 & 3,5 & $0,0-1,2$ & $60 \%$ \\
\hline \multirow{4}{*}{ 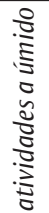 } & Fração Inalável & $0,5-24,0$ & 4,4 & 3,3 & $3,3-5,5$ & $25 \%$ \\
\hline & Fração Torácica & $0,2-11,0$ & 2,3 & 3,0 & $1,3-3,3$ & $*$ \\
\hline & Fração Respirável & $0,1-4,4$ & 0,9 & 2,5 & $0,1-1,7$ & $8 \%$ \\
\hline & Sílica & $N D-0,5$ & 0,1 & 3,0 & $0,0-1,2$ & $60 \%$ \\
\hline
\end{tabular}

ND = sílica não detectada por DRX

*Não há valor de referência para a fração torácica 
Tabela 5 Valores de concentração nas frações inalável, torácica e respirável e de probabilidade da concentração de exposição ultrapassar o valor de referência em uma marmoraria com processo de acabamento a úmido como medida de controle para a contenção da poeira, avaliada na cidade de São Paulo em outubro/2003

\begin{tabular}{|c|c|c|c|}
\hline Amostra / Ponto de Amostragem & $\begin{array}{c}\text { Concentração inalável } \\
\qquad\left(\mathrm{mg} / \mathrm{m}^{3}\right)\end{array}$ & $\begin{array}{c}\text { Concentração torácica } \\
\qquad\left(\mathrm{mg} / \mathrm{m}^{3}\right)\end{array}$ & $\begin{array}{c}\text { Concentração respirável } \\
\qquad\left(\mathrm{mg} / \mathrm{m}^{3}\right)\end{array}$ \\
\hline 1 / individual - acabador & 2,6 & 1,6 & 0,8 \\
\hline 2 / individual - acabador & 4,0 & 1,4 & 1,3 \\
\hline 3 / individual - acabador & 3,7 & 2,2 & 0,8 \\
\hline 4 / individual - acabador & 1,7 & 0,9 & 0,3 \\
\hline 5 / individual - acabador & 1,8 & 0,7 & 0,2 \\
\hline $6 /$ individual - cortador & 3,2 & 1,8 & 0,5 \\
\hline 7 / individual - cortador & 3,3 & 1,7 & 0,6 \\
\hline 8 / individual - cortador & 2,6 & 1,3 & 0,4 \\
\hline $9 /$ área de corte & 2,5 & 1,4 & 0,5 \\
\hline 10 /área de circulação & 1,4 & 0,5 & 0,2 \\
\hline 11 / área de circulação & 1,0 & 0,6 & 0,3 \\
\hline 12 / área de circulação & 1,1 & 0,6 & 0,2 \\
\hline Concentração média geométrica & 2,2 & 1,1 & 0,4 \\
\hline Desvio padrão geométrico & 1,6 & 1,6 & 1,8 \\
\hline $\begin{array}{l}\text { Probabilidade do valor de referência ser } \\
\text { ultrapassado }\end{array}$ & $0,07 \%$ & - & $0,08 \%$ \\
\hline
\end{tabular}

\section{Discussão}

Uma vez que as atividades e os procedimentos aplicados em cada uma das marmorarias eram similares, situações que não podiam ser observadas em uma determinada marmoraria, devido à fase do processo produtivo, foram medidas durante a avaliação em outra marmoraria. Dessa maneira, obteve-se um panorama geral da exposição dos trabalhadores nesse ramo de atividade, considerando as várias possibilidades das ocorrências típicas. Um diagrama genérico do lay-out das marmorarias é mostrado na Figura 2.

As variações nas concentrações de poeira apresentadas na coluna "concentrações mínima e máxima medidas $\left(\mathrm{mg} / \mathrm{m}^{3}\right)$ " da Tabela 4 foram influenciadas por fatores como o tipo de tarefa executada, o número de trabalhadores operando lixadeiras, os tipos de rochas trabalhadas, a proximidade entre as bancadas de trabalho, o ritmo de trabalho, a existência de ventilação natural favorável à dispersão da poeira, o posicionamento e a distância do sistema de exaustão em relação às fontes geradoras de poeira, a proporção de atividades executadas a úmido e o tamanho da marmoraria.
Um dos problemas observados na instalação dos sistemas de exaustão foi a necessidade de movimentação dos trabalhadores ao redor das bancadas de trabalho para a execução das tarefas. Devido a isso, a maioria dos captores desses sistemas eram posicionados muito afastados das bancadas. Assim, a poeira gerada pelas ferramentas manuais passava inicialmente pelas narinas dos trabalhadores antes de ser aspirada pela exaustão.

Nas marmorarias que adotaram sistema de exaustão do tipo tela, os filtros eram rapidamente impregnados pelo excesso de poeira gerada pelas lixadeiras, com evidente diminuição da eficiência de captura do particulado. Devido ao custo elevado, a troca dos filtros não era executada com a freqüência necessária, prejudicando a sua eficiência. Na marmoraria 5 (Tabela 3), a exaustão do tipo tela foi adotada em todo o setor de acabamento. Nesse caso particular, foi observado que o principal benefício foi de ordem geral. Nessa empresa, a poeira não se dispersava para os setores de corte e polimento de chapas que trabalhavam a úmido.

Algumas marmorarias estavam testando lixadeiras elétricas com abastecimento contínuo de água para a finalização do trabalho de acabamento, chamado de 


\section{Setor de acabamento}
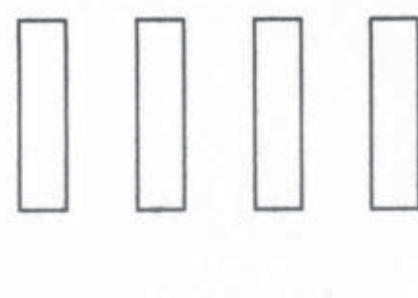

\section{área de circulação}
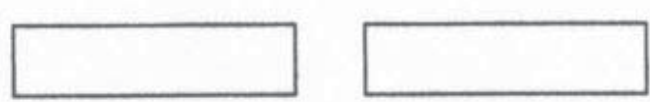

Setor de corte

\section{Depósito de chapas}

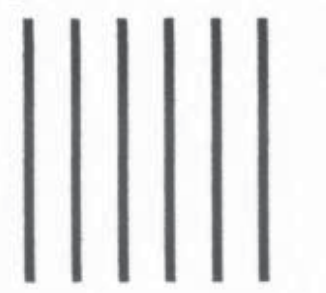

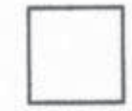

Furadeira

Figura 2 Distribuição típica dos postos de trabalho das marmorarias avaliadas

"brilho d'água”. Porém, essa tarefa era executada no meio do setor de acabamento, ao lado das lixadeiras convencionais que operavam a seco. Assim, a área de localização destas novas lixadeiras a úmido, as quais deveriam produzir uma baixa concentração de poeira, acabava sendo afetada pela poeira originada pelas lixadeiras a seco.

A ocorrência de altas probabilidades dos valores de referência serem ultrapassados, muito superiores aos 5\% propostos por Leidel, Bush e Lynch, (1977), mostra que na maioria das marmorarias as medidas de controle adotadas eram ineficientes ou insuficientes. Essas probabilidades estimam o risco de exposição dos trabalhadores para as condições ambientais e de trabalho encontradas durante o período de coleta das amostras.

Entre as marmorarias avaliadas, a concentração média de poeira inalável está duas vezes acima do valor máximo de referência adotado (LEO = $10 \mathrm{mg}$ / $\mathrm{m}^{3}$ ). Mas entre as amostragens realizadas nesse setor, foram encontrados valores 24,5 vezes maiores que o LEO para poeiras inaláveis. A Tabela 4 também mostra que a concentração para trabalhadores do setor de corte chegou a 2,4 vezes o LEO dessa fração em uma marmoraria na qual o sistema de controle estava desativado.

Destaca-se que, apesar de ainda não existir até o momento nenhum valor de referência para a fração torácica para qualquer tipo de poeira, as concentrações obtidas neste estudo representam registros para considerações futuras. No caso das marmorarias, esta pode ser uma informação importante, uma vez que a poeira dessa fração é capaz de penetrar e se depositar em regiões dos pulmões que são asso- ciadas com doenças que se desenvolvem juntamente com a silicose.

A quantidade média de poeira fina encontrada no setor de acabamento (representada pela concentração na fração respirável) seria crítica mesmo para poeiras que não contêm sílica. A concentração média de poeira respirável flutuou ao redor do valor de referência ( $\mathrm{LEO}=3 \mathrm{mg} / \mathrm{m}^{3}$ ), mas foram encontrados valores que chegavam a 10 vezes o LEO. Porém, devese lembrar de que a poeira gerada em marmorarias, de maneira geral, contém sílica. Portanto, as concentrações recomendadas para as frações inalável e respirável, mencionadas anteriormente, servem apenas como um indicativo das condições ambientais gerais. A poeira contendo sílica é classificada como pneumoconiótica e cancerígena e o limite de exposição (valor de referência) estabelecido na ocasião do estudo era de 0,05 mg/m $\mathrm{m}^{3}$ (ACGIH, 2005), lembrando que, a partir de 2006, o limite de exposição para sílica na forma de quartzo baixou para $0,025 \mathrm{mg} / \mathrm{m}^{3}$ (ACGIH, 2006).

Devido à grande diversidade de rochas trabalhadas nas marmorarias avaliadas, a concentração média de sílica variou em até 16 vezes o LEO. A probabilidade média desse valor ser ultrapassado variou de $60 \%$ a $84 \%$, sendo que o valor máximo atingido foi de 24 vezes o valor de referência. No setor de corte, os trabalhadores estavam expostos a uma concentração média de 1,4 vez o valor de referência. A poeira suspensa no ar das marmorarias avaliadas era composta de uma mistura contendo até $28 \%$ de sílica. Esse teor de sílica na poeira varia em decorrência da composição da rocha trabalhada. Isso explica a amplitude dos intervalos de confiança das médias obtidas para as concentrações de sílica, que podem variar desde zero, quando a rocha trabalhada é um 
mármore, até qualquer outro valor, dependendo da rocha e das condições ambientais.

A presença de sílica, na forma de quartzo, junto com outros minerais é freqüente em poeiras nos locais de trabalho onde se processam rochas. Mesmo que em proporções relativamente pequenas (menores que $10 \%$ ), o quartzo representa um risco significativo para a saúde do trabalhador exposto a uma elevada concentração total de poeira. Nessas circunstâncias, geralmente se recomenda a substituição ou a modificação de processos, operações e equipamentos com o objetivo de se conseguir apreciável redução na geração da poeira. Também se deve eliminar ou diminuir o contato físico entre os trabalhadores e o agente de risco. Obviamente, as modificações não devem introduzir novos riscos e devem ser tecnicamente factíveis a custos aceitáveis.

Comparando os dados apresentados nas Tabelas 4 e 5 , nota-se que a variabilidade geral dos dados de concentração, representada pelo desvio padrão geométrico, é menor com a umidificação completa do processo produtivo (corte e acabamento). Na marmoraria 4 , as concentrações médias obtidas para as frações inalável, torácica e respirável são muito inferiores e estão dentro dos limites utilizados como referências. Além disso, as amostras coletadas na área de circulação dos trabalhadores também mostram que a umidificação diminui a dispersão da poeira pelo ambiente de trabalho, conforme apresentado na Tabela 5.

Para as frações de poeira respirável e inalável, os valores de probabilidade do valor de referência ser ultrapassado mostram que a adoção da umidificação completa do processo produtivo pode reduzir a valores próximos de zero a probabilidade de sobreexposição nessas condições.

Uma limitação deste estudo foi a impossibilidade de se avaliar os níveis de concentração de sílica livre cristalizada com a implantação da umidificação no processo de acabamento, uma vez que, durante o período de avaliação, a marmoraria 4 estava trabalhando somente com uma encomenda de peças de mármore, material que não continha sílica.

Esses dados puderam ser compreendidos por meio de outros estudos realizados em marmorarias, como os de Simcox (1999) e os de Bon (2006). O estudo de caso realizado em Washington (SIMCOX, 1999) mostrou os resultados de avaliação das concentrações de sílica na fração respirável, tanto para o processo a seco, como para o processo a úmido em marmorarias, concluindo que a umidificação reduz significativamente a concentração de sílica, mas que cuidados complementares ainda deveriam ser adotados. Bon (2006) também realizou estudos para caracterizar a exposição dos trabalhadores a poeiras contendo sílica em marmorarias de São Paulo, mostrando as vantagens da umidificação nas atividades de marmorarias.

\section{Conclusões}

Os resultados obtidos a partir deste estudo demonstraram que os trabalhadores de marmorarias estão caracteristicamente expostos a altas concentrações de poeira extremamente fina. Essa poeira é gerada principalmente pelas ferramentas utilizadas para as atividades de acabamento a seco das rochas ornamentais. Os trabalhadores do setor de corte, apesar de trabalharem a úmido, também estão expostos a essa poeira que se dispersa por todo o ambiente em conseqüência das práticas de trabalho adotadas.

As concentrações nos ambientes de trabalho das marmorarias variavam dentro de uma ampla faixa de valores, seguindo uma distribuição lognormal. Entre todas as amostras analisadas, foram encontrados valores superiores em até 24 vezes o valor de referência genérico de $10 \mathrm{mg} / \mathrm{m}^{3}$ para a fração inalável e em até 10 vezes o valor de referência genérico de $3 \mathrm{mg} / \mathrm{m}^{3}$ para a fração respirável.

Entre as determinações realizadas, os resultados mais alarmantes foram os das concentrações de sílica livre cristalizada. Foram encontrados valores superiores em até 24 vezes o limite de exposição ocupacional de $0,05 \mathrm{mg} / \mathrm{m}^{3}$ para sílica (ACGIH, 2005). Devido às diferenças nas composições das rochas trabalhadas em marmorarias, os valores médios das concentrações variaram em até $1,2 \mathrm{mg} / \mathrm{m}^{3}$, tanto no setor de acabamento a seco, como no setor de corte a úmido das marmorarias convencionais.

A probabilidade do LEO para sílica ser ultrapassado, nas condições encontradas nas marmorarias com processo de acabamento a seco, foi de $60 \%$ a $84 \%$. Esse quadro mostrou que as medidas de controle por exaustão, adotadas por essas marmorarias, foram ineficientes ou insuficientes para a contenção da poeira e a diminuição da exposição ocupacional.

Considerando que, de modo geral, as marmorarias brasileiras não adotam nenhum tipo de medida de controle de caráter coletivo, pode-se inferir que a situação da exposição a poeiras no Brasil e, principalmente, à sílica deva ser ainda mais preocupante do que a que foi identificada por este estudo.

As medições realizadas não somente dão uma idéia aproximada do panorama das marmorarias da cidade de São Paulo, como podem ser um indicativo da provável situação de outras marmorarias do Brasil. A divulgação dessas informações serve como um alerta, pois se baseiam em dados concretos que podem ser utilizados como ponto de partida para a resolução do problema.

Uma alternativa para a minimização da exposição a poeiras foi testada com bons resultados. A adoção do processo de acabamento a úmido com lixadeiras pneumáticas reduziu para cerca de $0,1 \%$ a probabilidade das concentrações ambientais ultrapassarem os valores de referência para as frações inalável e respi- 
rável. A probabilidade para as concentrações de sílica não pode ser testada, pois a marmoraria avaliada trabalhava predominantemente com mármores.

A partir dos dados obtidos neste trabalho é possível perceber que é urgente a necessidade de modificação das marmorarias. Porém, essa modificação deve vir acompanhada da capacitação dos trabalhadores para a execução de suas tarefas, além da melhoria de insumos e ferramentas visando à redução da geração de poeira. A preocupação com a saúde e a segurança no trabalho não pode ser apenas uma exigência legal. Os donos de marmorarias devem compreender que, mesmo sendo microempresários, podem fazer muito para melhorar as condições de trabalho dentro de suas empresas.

Um estudo mais aprofundado sobre eventuais problemas causados pela umidade excessiva nas marmorarias que optarem pelo sistema de produção a úmido ainda é necessário, pois o trabalhador permanecerá em um ambiente bastante úmido durante toda a jornada de trabalho. Esse estudo deve incluir informações detalhadas sobre o tratamento e o reaproveitamento da água utilizada e a eventual contaminação dessa água por agentes biológicos.

\section{Agradecimentos}

Aos proprietários das marmorarias avaliadas, pela colaboração, permitindo o livre acesso da equipe de estudo e não interferindo ou alterando a rotina de trabalho da empresa durante o período de avaliação.

Aos trabalhadores, por seu comportamento amigável e prestativo em todas as solicitações dos técnicos de campo.

À Fundacentro que, por meio do projeto interno "Metodologias para Avaliação da Exposição Ocupacional a Poeiras", possibilitou a realização deste trabalho.

O pesquisador R. M. A., co-autor deste artigo, agradece ao CNPq pelo apoio financeiro.

\section{Referências}

ABIROCHAS. Associação Brasileira da Indústria de Rochas Ornamentais; CETEM. Centro de Tecnologia Mineral. Catálogo de rochas ornamentais do Brasil. São Paulo: ABIROCHAS/CETEM: Rio de Janeiro, 2003. 1 CD-ROM.

ACGIH. American Conference of Governmental Industrial Hygienists. 2006 Threshold limit values for chemical substances and physical agents and biological exposure indices. Cincinnati: ACGIH, 2006.

. 2005 Threshold limit values for chemical substances and physical agents and biological exposure indices. Cincinnati: ACGIH, 2005.

Particle size-selective sampling for healthrelated aerosols. Cincinnati: ACGIH, Air Sampling Committee, 1993-94.

BON, A. M. T. Exposição Ocupacional à Sílica e Silicose entre Trabalhadores de Marmorarias, no Município de São Paulo. 2006. 299f. Tese (Doutorado em Saúde Ambiental) - Faculdade de Saúde Pública, Universidade de São Paulo, São Paulo, 2006.

CEN. Comité Européen de Normalisation. EN481: workplace atmospheres: size fraction definitions for measurements of airborne particles in the workplace. Brussels, 1992.

IARC. International Agency for Research on Cancer. Silica and some silicates, coal dust and para-aramid fibrils. Lyon: IARC, 1997. 506 p. (IARC Monographs on the Evaluation of the Carcinogenic Risk of Chemicals to Humans, v. 48).

ISO. International Standard Organization. Air quality: particle size fraction definitions for healthrelated sampling. Genebra: ISO, 1992. Technical Report ISO/CD 7708.

LEIDEL, N. A.; BUSH, K. A.; LYNCH, J. R. Occupational exposure sampling strategy manual. Cincinnati: NIOSH. Department of Health, Education and Welfare, Public Health Service, Centers for Disease Control, 1977.

MELLO, I. S. C. Panorama setorial das rochas ornamentais do Estado de São Paulo. Revista Rochas de Qualidade, São Paulo, n. 154, p. 140-153, 2000.

MPESP. Ministério Público do Estado de São Paulo. Setor de Meio Ambiente e Prevenção de Acidentes. Promotoria de Justiça de Acidentes de Trabalho. Projeto Marmoristas: Relatório preliminar sobre o cadastro de trabalhadores. In: Oficina de Trabalho sobre o Programa Nacional de Eliminação da Silicose. Brasília, 2001.

SANTOS, A. M. A. Determinação quantitativa de sílica livre cristalizada por difração de raios X. Rev. bras. Saúde ocup., v. 17, n. 65, p. 55-59, 1989. 
. Norma de Higiene Ocupacional NHO-03: análise gravimétrica de aerodispersóides coletados sobre filtros de membrana. São Paulo: Fundacentro, 2001.

. Exposição ocupacional a poeiras em marmorarias: tamanhos de partículas característicos. 2005. 174f. Tese (Doutorado em Engenharia Metalúrgica e de Minas) - Escola de Engenharia, Departamento de Engenharia de Minas, Universidade Federal de Minas Gerais, Minas Gerais, 2005.

SIMCOX, N. J. et al. Silica exposure during granite countertop fabrication. Applied Occupational and Environmental Hygiene, v. 14, n. 9, p. 577-582, 1999.
TSI. Incorporeted, Health And Safety Instruments Division. How a virtual impactor works. TSI Application Note ITI-051. St. Paul, Minessota, 1997. Available from: http://www.tsi.com. Access: 20 abr. 2002.

VINCENT, J. H. Methodology for determining aerodispersoids exposure in work places. In: LEE, S. D. et al. Aerosols: research, risk assessment and control strategies. USA: Lewis Publ., 1986. p. 185202.

WILLEKE, K.; BARON, P. A. Aerosol measurement: principles, techniques and applications. New York: Van Nostrand Reinhold, 1993. 